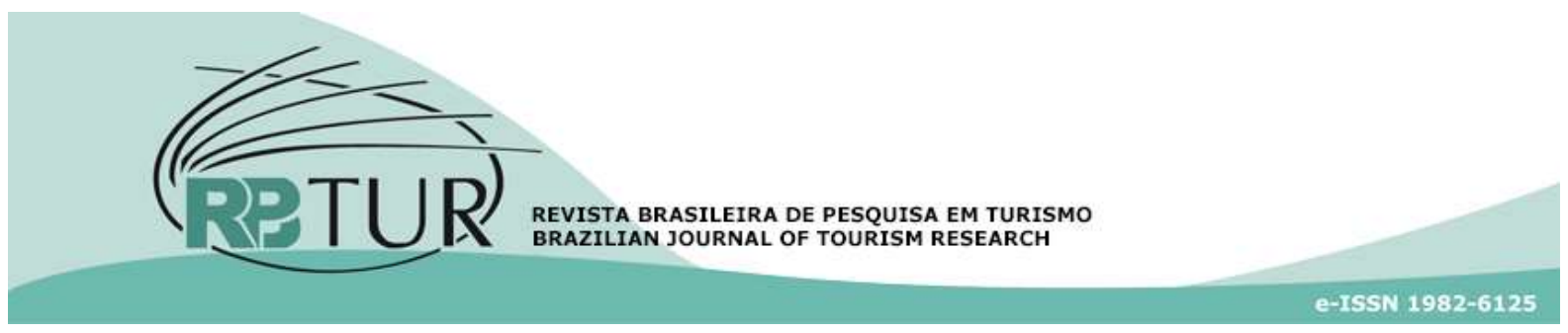

Artigo

DOI: http://dx.doi.org/10.7784/rbtur.v12i3.1446

\title{
O papel da mulher no turismo rural: um estudo no circuito Rajadinha de Planaltina - Distrito Federal
}

\author{
The role of women in rural tourism: a study in the Planaltina's \\ Rajadinha circuit - Federal Districts
}

\section{El papel de la mujer en el turismo rural: un estudio en el circuito Rajadinha de Planaltina - Distrito Federal}

\section{Donária Coelho Duarte ${ }^{1}$ Ana Darc Jesus Pereira ${ }^{2}$}

Resumo: Este estudo objetiva investigar a realidade das mulheres que trabalham no turismo rural da região de Planaltina-DF. Contribui, portanto, para a temática gênero e turismo, sobremaneira, relacionando ao turismo rural. Este, enquanto submodalidade do Turismo no Espaço Rural (TER), surge como segmento do campo e integra a gama de atividades não agrícolas que passaram a ser desenvolvidas no campo nos últimos anos como estratégia de manutenção e sobrevivência. Simultânea a essas mudanças funcionais do espaço rural, observamse novas formas de organização da vida familiar, no qual a proximidade entre as tarefas realizadas no ambiente doméstico com a atividade turística no meio rural permite a reestruturação das funções e da divisão de trabalho entre gêneros. Dessa forma, este estudo foi realizado no Circuito Rajadinha, Projeto criado em 2014 na região de Planaltina-DF. Das 10 propriedades que compõem o Circuito, oito participaram do estudo e dessas 10 mulheres foram investigadas. Este trabalho caracteriza-se como estudo de caso de cunho qualitativo. Aplicou-se um roteiro de entrevista semi-estruturado na busca de entender a realidade das mulheres que atuam diretamente no desenvolvimento do turismo rural no Circuito. Constatou-se que o turismo rural promovido estabelece uma relação positiva entre mulheres e homens envolvidos. Observou-se que no Circuito a mão de obra feminina não é vista apenas como atividade complementar, mas atua como elemento essencial para a manutenção do turismo rural nas propriedades investigadas e assume papel principal desse cenário rural.

Palavras-chave: Turismo no Espaço Rural. Turismo Rural. Estudos de Gênero.

Abstract: This study aims to investigate the reality of women working in rural tourism in the region of Planaltina,

${ }^{1}$ Universidade de Brasília - Campus Planaltina (UnB/FUP), Brasília, DF, Brasil. Definição do tema de estudo, do objetivo e escolha da metodologia. Orientação sobre a construção do roteiro de entrevista e estruturação do artigo. Orientação do trabalho como um todo e revisão de redação.

2 Universidade de Brasília - Campus Planaltina (UnB/FUP), Brasília, DF, Brasil. Construção do embasamento teórico, coleta de dados, análise e interpretação dos dados, conclusão.

Artigo recebido em: 23/04/2018. Artigo aceito em: 23/07/2018. 
Federal District (FD). It contributes, therefore, to the discussion of gender and tourism in the context of rural tourism. This, while sub-modality of Tourism in Rural Areas (TRA), is a segment of the countryside and includes the range of non-agricultural activities that have been developed in the rural areas in recent years as a strategy for maintenance and survival. Simultaneous with these functional changes of the rural space, new forms of organization of family life are observed, in which the proximity between the tasks performed in the domestic environment and rural tourism activities contributes to the redefinition of roles and gender division of labor. Thus, this study was carried out in the Rajadinha Circuit, a project created in 2014 in the region of Planaltina, FD. Of the 10 properties that make up the Circuit, eight participated in the study and 10 women were surveyed. This work is characterized as a qualitative case study. A semi-structured interview script was applied to understand the reality of women who work directly in the development of rural tourism in the Circuit. The results suggest that the rural tourism activities promoted a positive relationship between women and men involved. We observed that in the Circuit female labor is not just a supplementary activity, it is a key element for maintaining rural tourism on the farms studied and takes the leading role in this rural context.

Keywords: Tourism in Rural Areas. Rural Tourism. Gender Studies.

Resumen: Este estudio objetiva investigar la realidad de las mujeres que trabajan en el turismo rural de la región de Planaltina-DF. Contribuye, por lo tanto, a la temática género y turismo, sobremanera, relacionando al turismo rural. Este, mientras submodalidad del Turismo en el Espacio Rural (TER), surge como segmento del campo e integra la gama de actividades no agrícolas que pasaron a ser desarrolladas en el campo en los últimos años como estrategia de mantenimiento y supervivencia. Simultánea a estos cambios funcionales del espacio rural, se observan nuevas formas de organización de la vida familiar, en el cual la proximidad entre las tareas realizadas en el ambiente doméstico con la actividad turística en el medio rural permite la reestructuración de las funciones y de la división de trabajo entre géneros. De esta forma, este estudio fue realizado en el Circuito Rajadinha, Proyecto creado en 2014 en la región de Planaltina-DF. De las 10 propiedades que componen el Circuito, ocho participaron del estudio y de esas 10 mujeres fueron investigadas. Este trabajo se caracteriza como un estudio de caso de cuño cualitativo. Se aplicó un guión de entrevista semi-estructurado en la búsqueda de entender la realidad de las mujeres que actúan directamente en el desarrollo del turismo rural en el Circuito. Se constató que el turismo rural promovido establece una relación positiva entre mujeres y hombres involucrados. Se observó que en el Circuito la mano de obra femenina no es vista sólo como actividad complementaria, sino que actúa como elemento esencial para el mantenimiento del turismo rural en las propiedades investigadas y asume papel principal de ese escenario rural.

Palabras clave: Turismo en el Espacio Rural. Turismo Rural. Estudios de Género.

\section{INTRODUÇÃO}

Este estudo objetiva investigar a realidade das mulheres envolvidas no cenário rural da região de Planaltina - Distrito Federal (DF). Pretende discutir o papel das mulheres que atuam nesse cenário, entendendo a realidade vivida por elas no ambiente multifuncional do espaço rural.

Para tanto, optou-se por estudar a realidade de propriedades rurais que compõem o Circuito Rajadinha, Projeto criado em
2014 e coordenado pela Empresa de Assistência Técnica e Extensão Rural do Distrito Federal (Emater-DF), que possui o objetivo de promover o desenvolvimento das comunidades rurais situadas no Núcleo Rural Rajadinha I, Planaltina-DF, por meio do Turismo Rural.

Entende-se que o meio rural atrelado ao turismo deu origem a um novo segmento que vem se expandindo gradativamente. $O$ turismo desenvolvido no espaço rural é considerado uma atividade não agrícola e com- 
preende as práticas turísticas exercidas em áreas/ambientes rurais.

Assim, o turismo rural, compreendido como uma das modalidades turísticas desenvolvidas no espaço rural, refere-se ao conjunto de atividades do segmento turístico desenvolvidas no meio rural, no qual a produção agropecuária, entre outras atividades tradicionais ao campo compõe a sua prática.

Observa-se que o turismo rural promove benefícios tanto de âmbito econômico como social, pois além de gerar importantes índices para o crescimento econômico, como a geração de emprego e renda, é capaz de atuar também no âmbito social, uma vez que promove a melhoria da qualidade de vida dos moradores através da infraestrutura e promoção do retrocesso do êxodo rural.

Neste contexto, verifica-se que juntamente com o turismo rural surgem novas formas de organização da vida familiar, no qual a divisão do trabalho é afetada, onde a proximidade entre as tarefas realizadas no ambiente doméstico com a atividade produtiva rural permite a reestruturação das funções e divisão de trabalho entre gêneros.

Sob este aspecto, observa-se que durante anos mulheres e homens conviveram com uma divisão de trabalho regida pelo sistema de gênero, ao qual a força física necessária para realização de determinado trabaIho era usada como justificava, ou seja, se determinado trabalho necessitava de maior força física o homem era quem deveria realiza-lo, porém se fosse um trabalho "leve" caberia à mulher a execução. No entanto, atualmente observa-se que esta vem ocupando diversos cargos que antes eram exercidos exclusivamente por homens.
Dessa forma, este estudo objetiva investigar as trabalhadoras integrantes do Circuito Rajadinha - situado na região de Planaltina - DF, por meio da análise da sua inserção na força de trabalho. Com este intuito, este levantamento apresenta inicialmente um embasamento teórico acerca do turismo, do meio rural e do papel da mulher no mercado de trabalho, pressupostos necessários para entender como os atores sociais envolvidos no segmento do turismo rural atuam, sobremaneira a inserção da mulher no cenário do Circuito em questão.

\section{Abordagem conceitual: Turismo no Es paço Rural (TER) e Turismo Rural}

Nas últimas décadas o espaço rural foi abarcado pelas mudanças promovidas pelo processo de globalização e do advento da modernidade. Essas mudanças foram responsáveis pelo processo do êxodo rural, no qual muitos moradores do campo se evadiram aos centros urbanos na busca de trabaIho e melhoria de vida. Por outro lado, houve também aqueles preocupados com o desenvolvimento de estratégias de manutenção do campo, ou seja, os s que permaneceram no meio rural tiveram que desenvolver meios capazes de gerar renda e, consequentemente, de sobrevivência no espaço rural.

Verifica-se, portanto, que essas mudanças promoveram o estabelecimento de atividades não agrícolas no meio rural. Dessa forma, Santos et al (2014) apontam que com o desempenho de outras atividades econômicas no meio rural, conhecidas como atividades não agrícolas, os moradores do espaço rural passam a adquirir distintas fontes de 
rendimento, ou seja, a renda não é composta apenas da agricultura e da pecuária.

O turismo é um dos setores que mais sofre mudanças e deve estar em plena sintonia com o campo da inovação, já que se trata de um ramo altamente competitivo e que lida frequentemente com novas exigências de demanda. Assim, entende-se que o mercado turístico não se trata apenas de um mercado único, trata-se de um mercado segmentado que busca incessantemente atender as necessidades do consumidor.

Percebe-se, portanto, que o turismo no espaço rural compõe a gama de modalidades turísticas ao qual estabelece práticas relacionadas ao campo, proporcionando a participação dos turistas em atividades relacionadas ao meio rural.

Compreende-se que, embora muito parecidos, os termos "Turismo no Espaço Rural" e "Turismo Rural" propriamente dito, tem seus conceitos diferenciados. Enquanto o turismo no espaço rural abrange todas as modalidades possíveis de turismo exercidas no campo, o turismo rural seria uma modalidade, ou seja, pode ser considerado uma submodalidade dentro Turismo no Espaço Rural (TER).

Conforme Pato (2015), o termo Turismo no Espaço Rural pode ser compreendido como práticas turísticas exercidas em áreas rurais, que possuem uma vasta gama de sentidos e ambiguidade, o que não permite sua definição com precisão e clareza.

Dessa forma, compreende-se que o Turismo no Espaço Rural refere-se a toda e qualquer atividade turística desenvolvida no meio rural como o agroturismo e o próprio turismo rural (objeto do presente estudo).
Assim, pode-se dizer que o turismo no espaço rural integra a gama de atividades não agrícolas que podem ser exercidas no meio rural, sendo que este se torna multifuncional devido ao processo de modernização e industrialização. Santos et al (2014), consideram que:

O TER caracteriza-se por ser uma atividade não agrícola, que pode ser executada nas propriedades concomitantemente, em maior ou menor proporção, com as atividades agropecuárias, de industrialização, comércio e serviços, permitindo às famílias a oportunidade de atividades variantes e rendas complementares ao seu orçamento (Santos et al., 2014, p. 257).

Portanto, o turismo no espaço rural é uma atividade integrante do novo cenário do campo, atualmente marcado pela pluriatividade, ao qual deixa de ser um espaço da esfera produtiva, unicamente agrícola e passa a desenvolver atividades não agrícolas. $O$ turismo rural, por sua vez, pode ser compreendido como um segmento do setor turístico com alto potencial de desenvolvimento social e econômico. Do ponto de vista social, o turismo rural possibilita uma relação de trabalho formal e informal entre pessoas de qualquer raça, cor e gênero, além de favorecer a qualidade de vida dos adeptos ao setor. Já o cunho econômico desse segmento apresenta-se no alto potencial desenvolvimentista, com a geração de renda e emprego.

De acordo com Cezário, Mestre e Baptista (2015), o turismo rural refere-se ao conjunto de atividades realizadas por turistas no meio rural, no qual as atividades inerentes ao cotidiano no campo são desenvolvidas durante a visita. 
Portanto, enquanto o Turismo no Espaço Rural possui um sentido mais amplo, englobando qualquer tipo de atividade turística estabelecida no espaço rural, o turismo rural restringe-se aquela atividade turística desenvolvida no campo, no qual as atividades comuns ao meio rural, como agricultura, pecuária e etc. devem estar presentes na prática do turismo, ou seja, o turista exerce forte influência na execução das atividades da propriedade.

Acerca da diferenciação dos termos "Turismo Rural e "Turismo no Espaço Rural", Cezário, Mestre e Baptista (2015), consideram que o turismo rural, obrigatoriamente, deve estar ligado as atividades-fim desenvolvidas no meio rural, ou seja, atividades da pecuária e da agricultura, bem como serviços, provedores de valorização do patrimônio cultural e natural. Todos devem estar presentes durante a oferta da atividade turística. Já o termo Turismo no Espaço Rural refere-se as diferentes modalidades turísticas que podem ser propagadas no campo, direcionadas a lazer ou não. Necessariamente, precisa-se praticar atividades rotineiras do campo. Assim, o turismo ecológico, o agroturismo, o próprio turismo rural constituem a gama de atividades turísticas que podem ser desenvolvidas no campo mas que se diferem de acordo com sua natureza.

O turismo rural pode ser compreendido como uma alternativa às mudanças ocorridas nos últimos anos, às crises econômicas e ao processo de êxodo rural, uma vez que é uma forma de diversificação da fonte de renda dos adeptos ao campo. O campo torna-se um ambiente multifacetado, pois passa de um ambiente unicamente agrícola para um ambiente onde inúmeras atividades podem ser propagadas. Assim, o turismo rural é capaz de promover o retrocesso causado pelo êxodo rural, já que possibilita aos moradores urbanos a oportunidade de conviver com os costumes e tradições do campo e até mesmo promover o reencontro de suas raízes.

Uma vez compreendido como uma alternativa à migração do produtor para o meio urbano, o turismo rural pode ser conceituado como:

O conjunto de atividades turísticas desenvolvidas no meio rural, comprometidas com a produção agropecuária, agregando valor a produtos e serviços, resgatando e promovendo o patrimônio cultural e natural da comunidade (MTur, 2008 apud Maia, 2015, p. 7).

Dessa forma, verifica-se que o turismo rural é uma modalidade turística desenvolvida no campo no qual se estabelece o envolvimento do turista com a produção agrícola/agropecuária, ou seja, para ser considerado turismo rural se faz necessário que este esteja comprometido com as atividades rurais tradicionais ao campo que são praticadas no local.

De acordo com Cezário, Mestre e Baptista (2015), o turismo rural refere-se ao conjunto de atividades realizadas por turistas no meio rural, no qual as atividades inerentes ao cotidiano no campo são desenvolvidas durante a visita, ou seja, atividades tradicionais como a agricultura devem estar presentes. Sob este aspecto, constata-se que o campo foi afetado pelas diversas mudanças ocorridas nos últimos anos, no qual houve a necessidade de se estabelecer novas formas de sua 
manutenção. Surge, então, a necessidade de implantar novas atividades que sejam capazes de manter os moradores no espaço rural. Assim, o turismo rural pode ser compreendido como importante estratégia para atender a essas necessidades, pois segundo Ramalho (2015),

Um dos principais aspectos positivos do turismo é a capacidade de gerar emprego e renda, o efeito multiplicador, dentre outras perspectivas econômicas, que têm influenciado o incremento da atividade em posições estratégicas na economia de vários países (Ramalho, 2015, p. 225).

Portanto, observa-se que o turismo rural, enquanto atividade não agrícola, pode ser compreendido como estratégia de desenvolvimento local, uma vez que o segmento turístico possui ampla capacidade de gerar renda e emprego. Dessa forma, o atual meio rural, que foi abarcado pela modernidade, ao incrementar suas atividades promovendo a pluriatividade através do turismo rural, incentiva o aumento da economia, além de promover benefícios sociais, como a manutenção do campo, bem como melhoria na qualidade de vida aos adeptos do meio.

Embora seja relativamente recente, entende-se que turismo rural é uma atividade com alto potencial de desenvolvimento capaz de gerar índices consideráveis de renda e emprego. Dessa forma, Amaral (2016), considera que a inserção do turismo no meio rural reflete oportunidades como geração de empregos, criação de empreendimentos, além de promover o sustento dos ruralistas na medida em que as atividades tradicionais perdem importância.
Portanto, o turismo rural apresentase como uma oportunidade de mercado, uma vez que o meio rural deixou de ser um espaço unicamente agrícola tornando-se um ambiente multifacetado, no qual atividades não agrícolas com alto potencial de desenvolvimento, como o turismo rural, ganham cada vez mais espaço mercadológico. Portanto, o turismo rural proporciona o desenvolvimento econômico, pois favorece a geração de trabalho e, consequentemente, a geração de renda. Considera-se que o mesmo promove impacto social, com a redução do êxodo rural e inclusive a inserção da mão de obra feminina, objeto de estudo do presente trabalho.

Corroborando, Scótolo e Netto (2015) consideram que o turismo é uma forte estratégia de desenvolvimento, uma vez que esta atividade possui potencial para retificar desigualdades econômicas e sociais através da geração de emprego e renda. Assim, os locais onde se pode estabelecer a atividade turística podem ser beneficiados a partir da diversificação da economia local e da melhoria na qualidade de vida dos moradores da região.

Dessa forma, o turismo rural, enquanto atividade não agrícola com viés de cunho econômico e social, possui alto potencial desenvolvimentista. $\mathrm{O}$ mesmo tem contribuído para manutenção do emprego e da ocupação no espaço rural, além de promover o retrocesso do êxodo rural e promoção da melhoria na qualidade de vida dos moradores do meio rural através de infraestrutura, serviços públicos que são trazidos pela implementação das atividades turísticas. 
3 A QUESTÃO DE GÊNERO: O PAPEL DA MULHER NO TURISMO RURAL

Compreende-se que as relações de trabalho passaram por diversas mudanças ao decorrer dos últimos anos. A substituição cada vez mais crescente da força de trabalho pela tecnologia, causando o aumento de desemprego, bem como as reduções de postos de trabalho fizeram com que a sociedade recorresse a novas estratégias de sobrevivência.

Observa-se neste cenário a inserção da mão de obra feminina no mercado de trabalho, no qual Kloster et al (2015, p. 104) apontam que "atualmente não se podem negar os avanços das mulheres, sejam em áreas onde os homens estavam ao centro como principal elemento para exercer tal atividade, áreas tecnológicas e até mesmo no campo".

Entende-se, portanto, que existem avanços consideráveis da inserção da mão de obra feminina em áreas onde o homem era o principal elemento. Isto pode ser justificado também pela necessidade de complementação da renda familiar, configurando-se como importante impulsionador dessa inserção, uma vez que vivencia-se um cenário marcado por grandes taxas de desemprego e redução da renda familiar.

Sobre a inserção da mulher no meio rural, Alves, Lima e Nagabe (2016, p. 5) consideram que: Até pouco tempo as principais relações de trabalho no campo estavam relacionadas à gestão masculina, enquanto a presença das mulheres restringia-se à poucas ações, relacionadas principalmente às atividades domésticas, preparo de alimentos, cuidado com a lavoura de subsistência, criação de pequenos animais e produção de artesanato.

Analisando o pensamento desses autores, é possível inferir que a inserção da muIher no mercado de trabalho remete à questão da desigualdade entre os gêneros, no qual as diferenças entre o sexo masculino e feminino ditam paradigmas acerca de quem faz o quê, justificados por princípios baseados na força física necessária para realização de determinado trabalho.

Nesse contexto, durante anos, mulheres e homens desempenhavam papéis sociais muito diferentes, a mulher conviveu de forma "opaca" na sociedade, não tinha voz ativa e era vista, basicamente, como instrumento de procriação, ao qual tinha como obrigação apenas cuidar dos filhos e da casa. Atualmente é possível observar algumas mudanças que circundam este cenário. As muIheres geram e cuidam dos filhos, cuidam da casa, trabalham fora, pagam contas, votam, recebem salários, ou seja, deixaram de ser um instrumento reprodutivo e passaram a integrar diversos campos, atuando no mercado de trabalho.

Faria (2009 apud Nascimento, 2013) aponta que a divisão sexual do trabalho no cenário rural vincula o homem a esfera produtiva e a mulher a reprodutiva. Nesse contexto, o homem é o responsável por produzir, seja alimento, renda e etc., enquanto a muIher reproduz.

Assim, a presença da mulher em atividades rurais leva a uma nova estrutura na divisão de trabalho entre gêneros que deixa de lado a questão da divisão baseada na produção e na reprodução. Os papéis se alteram e a mulher passa a desempenhar funções pro- 
fissionais o que a torna mais um elemento de fonte de renda.

Conforme Freitas e Reis (2015), o processo de conquista do espaço profissional pelas mulheres nos últimos anos leva a uma mudança no perfil do mercado de trabalho e das relações sociais, uma vez que diversas profissões antes exercidas apenas pelo sexo masculino, hoje são exercidas, também, pelo sexo feminino.

Contudo, observa-se que ainda existem muitas desigualdades quanto a divisão de trabalho entre gêneros. Acerca disso, Herrera (2013) aponta que a força de trabalho feminina, apesar de ir além das práticas domésticas, é considerada, ainda, como conjunto de atividades invisíveis à sociedade.

Entende-se, portanto, que apesar de haver mulheres que exercem atividades inerentes ao campo como plantio, cuidado aos animais e colheita, o trabalho feminino como um todo não é ainda notado pela sociedade.

Ainda sobre a inserção da força de trabalho feminina, considera-se que "o crescimento da participação das mulheres no mercado de trabalho foi contribuído, também, pelo aumento do custo de vida e a monetarização da economia, forçando as muIheres a ajudarem no rendimento familiar" (Priore 1997 apud Ramos, Ulbanere \& Jesus, 2014, p. 4).

Dessa forma, compreende-se que, dentre as lutas feministas e outras manifestações em busca da igualdade de gêneros, a inserção da mulher no mercado de trabalho foi impulsionada, também, pelo aumento do custo de vida e da necessidade da complementação da renda familiar, ambos conse- quência do advento da modernidade e da globalização.

Entende-se que o processo de modernização afeta também as atividades exercidas no campo. A agricultura, principal segmento do meio rural brasileiro, deu espaço a um ambiente multifacetado, pois a mesma não atendia as necessidades dos ruralistas, havendo assim a necessidade de alternativas estratégicas de trabalho e sobrevivência no campo.

Neste contexto, Pato (2015) afirma que o espaço rural propiciou o estabelecimento de uma nova forma de turismo, no qual se apresenta como um produto sustentável e familiar, distinguindo-se, por essa via, dos demais segmentos turísticos que preenchiam o mercado.

Assim, com o desempenho de outras atividades econômicas no espaço rural, conhecidas como atividades não agrícolas, os moradores do campo adquiriram estratégias alternativas para ali se manterem, pois as atividades tradicionais não estavam sendo capazes de prover renda suficiente e o êxodo rural crescia amplamente.

Lunardi, Souza e Perurena (2015, p. 205) consideram ainda que:

Além do valor econômico, o turismo traz implícitos valores sociais e culturais, que significam mudanças positivas e negativas. Nesse sentido, há uma forte valorização social destacada pelas mulheres a partir do convívio com os turistas. Hoje, o turismo é visto, especialmente pelas mulheres, não só como uma fonte de recurso econômico para a família, mas também como uma fonte de conhecimento cultural, de redução do isolamento e de envolvimento social (socialização). 
Portanto, no arcabouço da modernidade o turismo ao ser implementado no espaço rural, integra a multifuncionalidade do campo e ainda impulsiona a expansão do fenômeno introdutor da mão de obra feminina no mercado de trabalho. Neste contexto, a mulher exerce um papel social de suma importância no setor, que por sua vez contribui para a construção de sua atual identidade social.

Neste cenário, Lunardi, Souza e Perurena (2015) argumentam que o turismo rural possibilitou um processo de mudança da identidade social e profissional do ser humano, no qual a mulher é inserida significativamente no mercado de trabalho e é reconhecida como empresária do turismo, reforçando sua identidade de agricultora, uma vez que o turismo rural tem como principal característica a relação direta com alguma atividade tradicionalmente exercida no campo.

Portanto, o turismo rural não pode ser considerado, apenas, como um segmento a mais na gama de atividades que compõem o mercado. Trata-se de um segmento formal de cunho econômico e social, uma vez que envolve capital e pessoas. Mostra-se como um importante provedor da igualdade nas relações de trabalho entre o homem e a muIher. Esta assume um papel principal nas relações de trabalho no atual cenário multifuncional do meio rural, construindo de forma consistente sua identidade social e profissional no mercado de trabalho.

Sob este aspecto, Schmitz e Santos (2013), mencionam que a força de trabalho feminina em atividades agrícolas é vista apenas como complemento, assim o homem, de- tentor da mão de obra considerada necessária para a execução dessas atividades é evidenciado como "chefe da família", pois seria o que tem o poder na tomada de decisões referentes à unidade de produção.

Considera-se que, embora ainda existam muitas diferenças entre os gêneros que compõem a força de trabalho, o turismo rural configura como uma importante área na qual a mulher pode desempenhar papel atuante, realizando funções profissionais que impactam economicamente e socialmente, o que a faz atuar de forma igualitária em relação ao gênero oposto.

\section{METODOLOGIA}

Este artigo tem como objetivo analisar o processo de inserção da mulher no âmbito do turismo promovido no Circuito Rajadinha, situado no Núcleo Rural Rajadinha I em Planaltina DF. Para atingir tal objetivo o método empregado foi o dedutivo.

O método dedutivo, de acordo com o entendimento clássico, é o método que parte do geral e, a seguir, desce ao particular. A partir de princípios, leis ou teorias consideradas verdadeiras e indiscutíveis, prediz a ocorrência de casos particulares com base na lógica (Prodanov \& Freitas, 2013, p. 27).

Dessa forma, para elaboração inicial do estudo foi realizada pesquisa teórica sobre os temas turismo rural, a relação entre gênero no espaço rural e o papel da mulher no turismo rural. Com base nesse levantamento teórico e, portanto, genérico, foi possível analisar os dados coletados de forma específica no Circuito Rajadinha. Enfatiza-se a 
importância da pesquisa teórica que deu robustez a análise de dados realizada.

O presente trabalho caracteriza-se como estudo de caso de cunho qualitativo. Oliveira (2011) aponta que esse tipo de pesquisa deve ser realizada em contato direto com o ambiente natural do objeto de estudo e que a mesma visa coletar dados e informações descritivos. Considera-se que esta pesquisa se enquadra como qualitativa, pois verificou-se a inserção da mulher no mercado de trabalho no turismo rural a partir do levantamento do relato das experiências vivenciadas pelas mulheres trabalhadoras que estão inseridas no Circuito Rajadinha.

Para a coleta de dados, das dez propriedades que compõem o Circuito, realizouse a pesquisa em oito estabelecimentos. Para essas, foi aplicado um roteiro de entrevista in loco, sendo que em duas propriedades a pesquisa foi realizada via telefone. Nos oito estabelecimentos investigados analisou-se a realidade de dez mulheres atuantes no turismo rural do Circuito.

Para a realização da pesquisa de campo, utilizou-se a entrevista, considerada uma das técnicas da pesquisa qualitativa. Sobre esta, Cervo \& Bervian apud Guerra (2014) consideram que:

A entrevista é uma oportunidade de conversa face a face, utilizada para "mapear e compreender o mundo da vida dos respondentes", ou seja, ela fornece dados básicos para "uma compreensão detalhada das crenças, atitudes, valores e motivações" em relação aos atores sociais e contextos sociais específicos (Cervo \& Bervian, 2007 apud Guerra, 2014, p. 18).

A opção pela aplicação de um roteiro de entrevista deu-se em virtude da necessidade de analisar in loco a realidade de cada mulher envolvida no turismo rural desenvolvido no Circuito Rajadinha. Todas as entrevistas foram realizadas entre os meses de abril e maio de 2017.

A entrevista semi-estruturada foi delineada com questões abertas. Foi dividida em dois blocos, nos quais a primeira parte direcionou-se aos proprietários das chácaras envolvidas no Circuito, com o objetivo de caracterizar essas propriedades, bem como seus respectivos donos, além de verificar a visão destes em relação a mão de obra feminina que atua em sua propriedade.

A segunda parte do roteiro foi direcionado especificamente as mulheres trabaIhadoras, onde buscou-se identificar a realidade de dez mulheres que estão envolvidas diretamente no turismo rural do Circuito. Nesse bloco foram apresentadas questões em relação ao seu histórico no mercado de trabalho, suas perspectivas e opiniões acerca da sua inserção no mercado de trabalho, mais precisamente no segmento do turismo rural. Além da entrevista direcionada aos proprietários e as mulheres que compõem o Circuito, foi realizada uma entrevista com a coordenadora do Projeto do Circuito, a turismóloga da Emater-DF, no intuito de buscar dados sobre o surgimento e objetivos do Projeto em análise.

\section{O CIRCUITO RAJADINHA}

Este capítulo visa caracterizar o Circuito Rajadinha, objeto de estudo do presente trabalho. Assim, pretende-se entender qual a proposta do Circuito Rajadinha, bem 
como obter informações acerca de suas características e peculiaridades.

A Secretaria Especial de Agricultura Familiar e do Desenvolvimento Agrário MDA (2017), aponta que o Circuito Rajadinha trata-se de um projeto na área de turismo rural, que é coordenado pela a EMATER-DF, mais precisamente pelo escritório da empresa situada em Planaltina- DF.

Ainda segundo o MDA (2017), o Circuito Rajadinha faz parte do projeto "Caminhos Rurais do DF". De acordo com a turismóloga da EMATER-DF que coordena o Circuito, "esse projeto foi criado em 2014 e se trata de uma proposta de trabalho na área de Turismo Rural da EMATER-DF e visa integrar atividades turísticas aos arranjos produtivos locais da agricultura familiar e incentivar a comercialização da produção associada ao turismo".

Considera-se que o Circuito Rajadinha é relativamente novo, criado em 2014. Acerca disso, Martimon (2016), aponta que sendo o primeiro circuito turístico do projeto maior "Caminhos Rurais do DF", o Circuito Rajadinha é formado atualmente por dez propriedades, situadas na Colônia Agrícola Rajadinha I, cerca de 40 quilômetros da cidade de Planaltina-DF, que integram o Circuito com diferentes ofertas de produtos e serviços turísticos.

De acordo com a Coordenadora do Projeto,

essas propriedades são de agricultura familiar, ou seja, os proprietários promoviam a agricultura e a implantação do turismo nesses espaços surgiu como oportunidade de complementar a renda dessas famílias. Assim, anualmente ocorre uma feira ao qual as propriedades que integram o Circuito Rajadinha se unem para promover a Colônia Agrícola Rajadinha I, ao qual diversas atividades inerentes ao turismo rural são ofertadas, como oficinas, visitas as chácaras do circuito, além da venda de artesanato, produtos orgânicos e do café colonial.

Como apontado anteriormente, o Circuito Rajadinha é constituído atualmente por dez propriedades. Conforme pode ser observado na Figura 1, constata-se que há uma proximidade entre a região de Planaltina DF e as propriedades que integram o Circuito Rajadinha.

Segundo a Coordenadora do Projeto, "as dez propriedades que compõem o Circuito Rajadinha são: Chácara Flora Brasília; Sítio Florida; Chácara Fernandes; Chácara Nossa Senhora Aparecida; Chácara Ouro Verde; Chácara LR; Frelmam Jardins; Chácara Serra Linda; Chácara Vida e Luz e Chácara Isasbelas". Para a Coordenadora, "atualmente o Circuito Rajadinha conta com 10 propriedades mas é um Circuito aberto, ou seja, no futuro pode ser que mais propriedades façam parte do mesmo". Ressalta-se que essas dez propriedades são situadas na região de Rajadinha I e que estas são próximas, conforme pode ser observado na Figura 2.

Esse fato facilitou a criação do Circuito.

Observa-se que o Circuito Rajadinha promove o turismo rural nas propriedades apresentadas na Figura 2. Quando questionada sobre o impacto que o Circuito trouxe para as mulheres que lá trabalham, a Coordenadora do Projeto considera que: "a partir do Circuito percebi uma mudança das mulheres que trabalham nas propriedades, porque antes elas eram muito retraídas e a partir do 
momento que elas se inseriram no turismo rural por meio do Circuito elas passaram a ter uma autoestima maior, passaram a querer falar em público, a querer tirar fotos porque antes eram mulheres que se escondiam atrás do trabalho e não mostravam que eram elas também as responsáveis pelo sucesso do Circuito".

Figura 1 - Trajeto Circuito Rajadinha

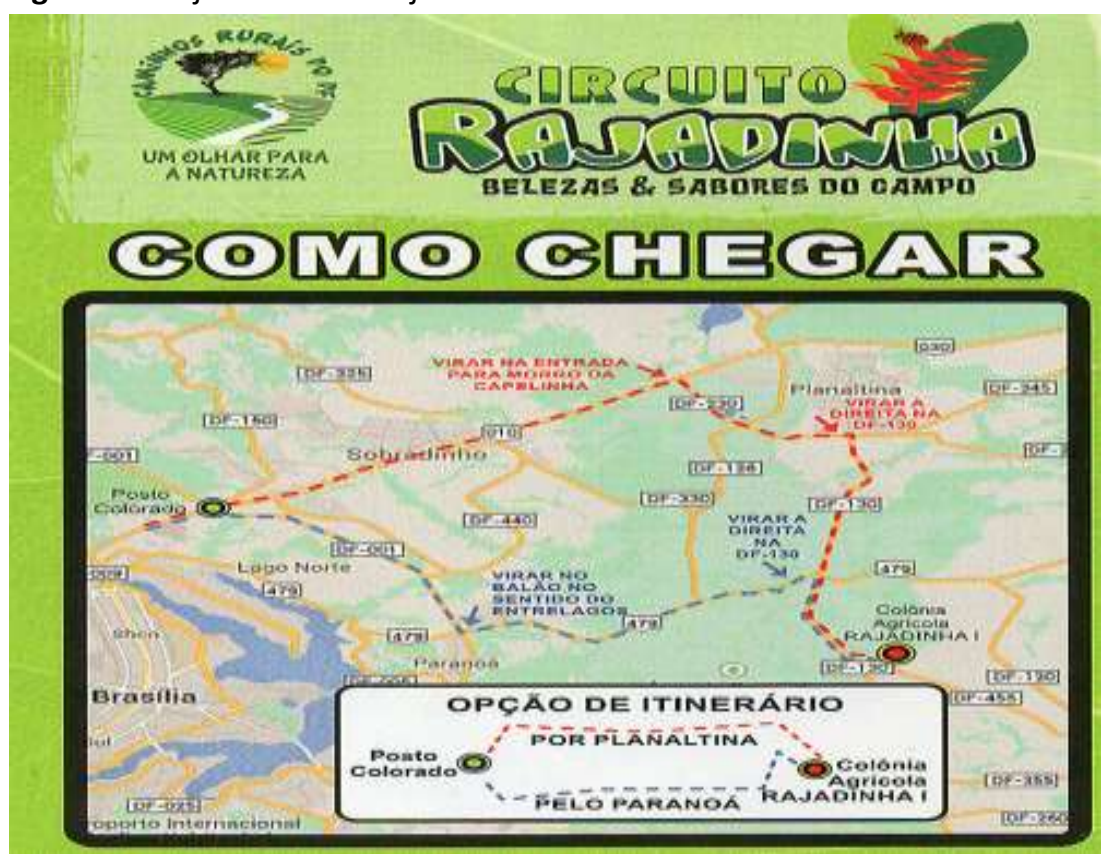

Fonte: Chácara Isasbelas. Circuito Tur (2017)

Figura 2 - Propriedades que compõem o Circuito Rajadinha

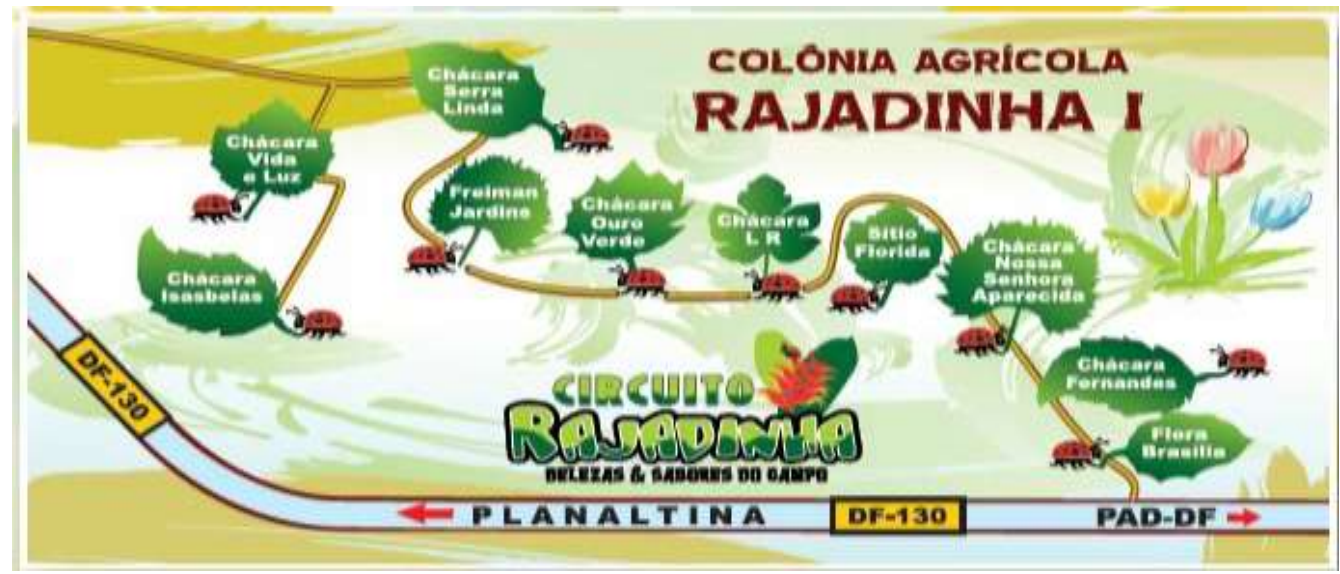

Fonte: Martinon (2017)

A partir desse relato da Coordenadora do Projeto constata-se a importância que o trabalho trouxe para vida das mulheres atuantes no Circuito, como o mesmo modificou a postura delas, o seu empoderamento, a sua atuação, segurança e autoestima. Isso confirma o impacto social que o trabalho por meio do turismo rural proporcionou para as 
entrevistadas.

A seguir essas propriedades serão investigadas de forma mais profunda.

\section{AS PROPRIEDADES INVESTIGADAS}

Na primeira parte da entrevista, direcionado especificamente ao proprietário do estabelecimento, constatou-se que duas propriedades são conduzidas diretamente por mulheres, ou seja, são as mulheres que estão à frente do espaço rural. Observou-se ainda que as demais propriedades, ao qual homens são proprietários, estes são casados. Assim, nota-se a presença das mulheres em todas as propriedades que compõem o Circuito Rajadinha, seja como proprietárias diretas ou como co-proprietárias.

Dessa forma, entende-se que o turismo no espaço rural é uma atividade integrante do novo cenário do campo que, por sua vez, reconduz uma relação mais uniforme entre a mulher e o campo, pois durante anos o principal elemento de força de trabalho atrelado ao meio rural era o homem. Assim, no Circuito Rajadinha é possível perceber que existe a presença da mulher como elemento principal no que tange ao gerenciamento de duas propriedades investigadas.

Verificou-se que os proprietários têm idade entre 45 e 72 anos, com grau de instrução baixo, ou seja, são pessoas com baixo nível de escolaridade, restringindo-se ao nível fundamental. Dessa forma, infere-se que os proprietários investigados das chácaras que compõem o Circuito Rajadinha, homens e mulheres, possuem um nível de escolaridade baixo.
As atividades que são desenvolvidas pelos envolvidos no Circuito são de acordo com cada produto turístico a ser ofertado, tanto na época da colônia, como também durante $\mathrm{o}$ ano, através da venda direta na propriedade ou em feiras. Quanto às atividades desenvolvidas nas propriedades, identificouse o cultivo de plantas ornamentais promovido por cinco propriedades; criação de pássaros exóticos; eventos com café colonial, floricultura e laticínios; paisagismo; espaço de recepção para alimentação; produtos orgânicos e locação de espaço para eventos.

Todas as propriedades entrevistadas ingressaram no Circuito Rajadinha, aproximadamente, há 2 a 3 anos, por intermédio da EMATER-DF. Ou seja, estas propriedades foram pioneiras no Circuito Rajadinha, uma vez que o projeto foi criado no ano de 2014. É consenso entre as propriedades visitadas que, anterior ao Circuito Rajadinha, nenhuma outra forma de turismo rural era estabelecida nessas propriedades. Os proprietários praticavam a agricultura para subsistências e até mesmo trabalhavam fora de suas propriedades para sustentar-se.

\section{PERCEPÇÃO DOS PROPRIETÁRIOS SOBRE O PAPEL DA MULHER NO CIRCUITO RAJA- DINHA}

Segundo autores, como Kloster et al. (2015) e Freitas e Reis (2015), as relações de trabalho passaram por diversas mudanças ao decorrer dos últimos anos e, cada vez mais, a figura feminina é vista atuando em diversas áreas, inclusive naquelas ao qual o homem era o único detentor da força de trabalho. Dessa forma, de acordo com os proprietários 
entrevistados, as mulheres que atuam no Circuito Rajadinha são elementos essenciais para o bom andamento das atividades fins de cada propriedade. Segundo um dos entrevistados "[...] ela sempre me ajudou e vai continuar sendo assim sempre, porque se hoje a gente está onde está foi porque trabalhamos juntos, eu sozinho não ia conseguir".

Este relato revela a importância que o proprietário de um dos estabelecimentos investigados dá a mão de obra feminina, no caso, a sua companheira, para o sucesso do seu empreendimento rural. Neste sentido, percebe-se que, apesar de ainda existirem preconceitos com relação a força de trabalho da mulher no campo, ao qual, segundo Herrera (2013), a mão de obra feminina no espaço rural é invisível à sociedade, observa-se nesta entrevista que a mão de obra feminina, considerada muitas vezes apenas como uma ajuda no complemento de renda familiar, é vista aqui como elemento essencial, segundo um dos proprietários que participam do turismo rural no Circuito Rajadinha.

De acordo com os demais entrevistados, percebe-se que as mulheres que exercem alguma atividade que integra o turismo rural do Circuito são reconhecidas pelos seus trabalhos. Todas foram avaliadas pelos proprietários de forma positiva, inclusive sendo apontadas como elemento significativo e essencial.

A inserção da mulher enquanto elemento considerado essencial pelos proprietários entrevistados remete ao reconhecimento da força de trabalho feminina, bem como o reconhecimento por parte dos envolvidos no Circuito Rajadinha de que as mulheres que ali atuam não só são capacitadas, como também são elementos chave para o alcance de objetivos do empreendimento. Isso pode ser evidenciado em trechos da entrevista, no qual um dos proprietários, quando questionado sobre o que teria a dizer em relação a inserção da mão de obra feminina no turismo rural da sua propriedade, menciona que: "[...] em primeiro lugar, positivo. Se eu colocar outro, não vai fazer o que ela faz [...]". Complementando, outro entrevistado menciona que "muita coisa melhorou aqui na propriedade com a participação da mulher nas atividades que fazemos".

Na mesma linha, ainda outro entrevistado aponta: "[...] mulher tem o dom de ser cuidadosa com a família e tudo que ela faz para a família ela vai fazer com carinho, por isso que o nosso trabalho tá dando certo [...]". Assim, observa-se que as mulheres atuantes no turismo rural do Circuito são avaliadas positivamente pelos proprietários das chácaras visitadas.

Portanto, infere-se que a mulher encara hoje um cenário mais aberto, com visões de que ela desempenha um papel importante no campo, onde o homem sempre foi elemento chave. Assim, as mulheres que integram a força de trabalho do Circuito Rajadinha são reconhecidas, além de gerar e cuidarem dos filhos, a atuar brilhantemente no campo e, consequentemente, no mercado de trabalho.

Conforme apontado por Faria (2009 apud Nascimento, 2013), o homem é responsável pela produção e a mulher pela reprodução, porém dentre as propriedades investigadas, identifica-se a presença da mão de obra feminina como elemento único na cadeia produtiva, pois em duas propriedades que 
compõe o Circuito a figura feminina esta a frente das atividades praticadas nas propriedades.

\section{A VISÃO DAS MULHERES ENVOLVIDAS NO CIRCUITO RAJADINHA}

Este capítulo tem por objetivo caracterizar as mulheres atuantes no turismo rural das propriedades que compõem o Circuito Rajadinha, discutir como se deu a sua inserção no mercado de trabalho e a sua relação com o turismo rural.

No início das entrevistas, mesmo não sendo questionadas sobre isso, algumas muIheres enfatizaram o papel da Emater no desenvolvimento do Projeto Circuito Rajadinha. Uma delas afirma que "a Emater ajudou muito, mudou a visão de trabalho, de trabaIhar com outras coisas na propriedade". Outra enfatiza que "a Emater sempre atua de forma exemplar junto a minha propriedade". Com base nesses relatos, constata-se o importante papel da Emater no desenvolvimento desse Projeto, pois o apoio técnico dado a essas propriedades que trabalham com o turismo rural propiciam mais segurança na atuação do ramo.

Verifica-se que as mulheres que atuam diretamente no Circuito Rajadinha possuem entre 44 a 70 anos de idade. São mulheres casadas ou viúvas que possuem apenas o nível fundamental. Além de desenvolver as atividades referentes ao turismo rural, essas mulheres desenvolvem outras atividades de cunho doméstico como cuidados com a família, filhos e casa.

A coleta de dados realizada aponta que a maioria das entrevistadas nunca tive- ram a oportunidade de inserir-se no mercado de trabalho. De um total das dez mulheres pesquisadas, apenas três apontam que já atuaram no setor industrial e no segmento doméstico.

Quando questionadas se na família já haviam mulheres que trabalhavam no turismo rural, uma das entrevistadas relata que "não porque na minha família há a falta de estudo, a falta de oportunidade para entrar no mercado de trabalho e a falta de apoio, pois a família não me deixava trabalhar".

Da mesma forma, em outro depoimento uma entrevistada relata que:

entrei no mercado de trabalho porque precisava fazer algo remunerado, antes não tive oportunidade devido a falta de estudo e meu marido não me deixava trabalhar. Considero que a mulher enfrenta desafios para entrar no mercado de trabalho e é preciso ter coragem para enfrentar o preconceito, além de muita força de vontade.

Esses relatos demonstram as dificuldades que essas mulheres tiveram para ingressar no mercado de trabalho. O preconceito, a falta de apoio da família e falta de es tudo são apontadas como algumas dificuldades relatadas pelas entrevistadas.

Sobre a importância do turismo rural para a inserção no mercado de trabalho, uma das entrevistadas aponta que "o turismo rural foi importante na minha inserção no mercado de trabalho, se não fosse isso eu teria que ficar cuidando da casa. Hoje tento conciliar as atividades da propriedade com as atividades de casa, do esposo, mas eu arrumo tempo para tudo". Na mesma linha, outra entrevistada menciona que "o turismo rural foi importante para a minha inserção no merca- 
do de trabalho, se não fosse ele eu teria que ficar só cuidando da casa".

Com base nesses depoimentos constata-se que, por meio do turismo rural, essas mulheres conseguiram ingressar no mercado de trabalho e hoje conseguem conciliar suas atividades profissionais com os afazeres familiares. Apesar de mais tarefadas, essas muIheres se mostram satisfeitas com esse dessa fio que the foi imposto de conciliar trabalho e família.

Sobre as dificuldades de permanência no ramo, uma entrevistada relata que não sofre muitas dificuldades para a sua permanência no turismo rural mas que "as vezes só na questão da falta de dinheiro e a falta de água - questões ambientais que dificultam a permanência no setor". Já outra entrevistada enfatiza que: "O turismo rural é pouco conhecido então a renda não dá conta, a renda advinda do turismo rural ainda é pouca e dependemos de questões climáticas, ainda há pouco reconhecimento do nosso trabalho, é necessário ter muita persistência. Mas espero melhoras futuras, que o turismo rural se desenvolva trazendo mais qualidade de vida".

Entretanto, a visão de outra entrevistada é diferente ao afirmar que "o turismo rural facilitou o meu ingresso no mercado de trabalho. Hoje em dia está bem reconhecido".

Infere-se que a necessidade de desenvolver novas estratégias de sobrevivência e de manutenção do meio rural de forma a possibilitar a permanência dos adeptos no campo pode se visto como impulsionadores do processo de inserção da mulher no mercado de trabalho. Tal fato é congruente ao pensamento de Priore (1997 apud Ramos, UIbanere \& Jesus, 2014), que considera que a entrada da mulher no mercado de trabalho se mostra cada vez mais crescente e pode ser explicada pela necessidade de se complementar a renda familiar devido o aumento do custo de vida e da evolução das estruturas econômicas.

No entanto, apesar da pesquisa identificar que as mulheres envolvidas no turismo rural do Circuito Rajadinha buscaram a inserção no mercado de trabalho por meio do setor turístico, visando um incremento na renda da família, bem como melhorias na qualidade de vida, os resultados dessa inserção tomaram rumos diferentes. Segundo uma das entrevistadas, a sua inserção resultou em algo a mais que isso pois, apesar da renda total da família não ter mudanças consideráveis, a qualidade de vida melhorou na medida em que adquiriu-se algo que considera mais importante: a experiência e a facilidade em relacionar-se com outras pessoas. Essa entrevistada relata que "[...] não tenho estudo, então eu não sabia nem como me relacionar com as pessoas direito, não entendia muita coisa e hoje eu posso dizer que eu entendo de alguma coisa [...]". Nessa mesma linha, outra entrevistada, quando questionada sobre a sua inserção no mercado de trabalho, relata que "melhorou a minha capacitação profissional, mudou a minha perspectiva futura, aprendizagem e capacitação. Um novo horizonte se abriu, agora tenho valor pelo que faço".

Tendo como base os relatos apresentados pelas entrevistadas, percebe-se que essas mulheres sentem prazer em estar no mercado de trabalho e que essa inserção 
trouxe ricos benefícios, muitos intangíveis, como o crescimento individual e uma nova perspectiva.

Ainda nessa vertente, uma outra entrevistada menciona que a inserção no mercado de trabalho por meio do turismo rural: "me ajudou muito, com o turismo rural adquiri experiência, percebi a importância de cuidar da natureza, houve melhoria na qualidade de vida minha e da minha família. Percebo um futuro promissor com o turismo rural e não vejo dificuldades em permanecer nesse ramo".

Ainda sobre a inserção no mercado de trabalho por meio do turismo rural uma entrevistada relata "é muito bom ser reconhecida, o trabalho facilita muito a minha vida, não pretendo sair desse ramo". Outra relata que "a implantação do turismo rural influenciou a minha inserção no mercado de trabaIho, se não fosse o turismo rural não haveria um maior conhecimento sobre o ramo da propriedade".

Os relatos apresentados mostram que o turismo rural desenvolvido por estas propriedades que compõem o Circuito estabelece uma relação de autoestima para as mulheres que ali atuam, pois reconhecem que hoje elas possuem um maior conhecimento, sentem-se a vontade para conversar e relacionar-se com outras pessoas. Se sem tem úteis no trabalho que desempenham.

Tais relatos são congruentes com o pensamento de Freitas e Reis (2015), que afirmam que houve uma mudança no perfil do mercado de trabalho e das relações sociais, áreas onde o homem era elemento principal estão sendo ocupadas por mulheres. Este fato foi confirmado no Circuito Rajadi- nha, uma vez que em todas as propriedades investigadas a força de trabalho feminina se faz presente e essas mulheres desenvolvem atividades que antes eram executadas pelo sexo masculino, como capina, plantio e coIheita.

Apesar do turismo rural implementado nas propriedades visitadas possibilitar benefícios individuais às mulheres envolvidas, as entrevistadas, em sua maioria, apontaram embates e desafios para a sua manutenção no segmento do turismo rural. Dessa forma, os desafios enfrentados pelas entrevistadas, sempre citados por elas, foram a falta de estudo e o preconceito machista contra a mulher. Uma entrevistada menciona que: "[...] o preconceito surgiu desde o momento que meu pai não deixava a gente ir pra escola, pois dizia que mulher tem que ficar em casa, assim não tive a oportunidade de estudar". Outra entrevistada relata que "com certeza, sofri preconceito, dificuldade de locomoção e a dificuldade de cuidar dos filhos e de trabalhar".

Entende-se que a relação da mulher com o mercado de trabalho ainda pode ser considerada instável. A prova disso são os desafios vivenciados por uma pequena parte de mulheres, essas aqui entrevistadas. Porém, conforme Lunardi, Souza e Perurena (2015), o turismo estabelecido no meio rural é detentor de valores sociais que permitem mudanças positivas quanto a essa relação. Nesta linha, uma entrevistada menciona que: "[...] dificuldades a gente encontra diariamente e no nosso trabalho a gente encontra também, mas não desanimo porque já ganhei muito até chegar aqui e posso ganhar mais [...]".

Conforme apontado por Schmitz e 
Santos (2013), a força de trabalho desempenhada pela mulher no ramo agrícola e no meio rural como um todo é vista como um complemento, ou seja, o homem é detentor da força de trabalho com maior expressão e, por isso, é ele quem tem o poder na tomada de decisões referentes à unidade de produção. Porém, na realidade de cinco propriedades que compõem o Circuito Rajadinha é possível constatar a quebra desse paradigma, no qual são mulheres que estão à frente das atividades relacionadas ao turismo rural, conduzindo toda a cadeia de produção. Ainda, existem duas chácaras que são as mulheres as proprietárias, ou seja, todas as atividades inerentes ao campo são conduzidas por estas. Uma propriedade visitada, por exemplo, é conduzida por uma mulher, ao qual oferta biscoitos caseiros e outros produtos em época de colônia e o cultivo de plantas ornamentais. Assim, com a ajuda indireta de uma filha, ela desenvolve todo o processo de cultivo das plantas, desde a criação de mudas, cuidados necessários às plantas, até a venda em feiras, na colônia do Circuito Rajadinha ou na própria propriedade.

Todas as entrevistadas atuam em diferentes partes da cadeia produtiva dos seus respectivos negócios, como mencionado anteriormente. As propriedades são de agricultura familiar, assim no turismo rural não é diferente, a família atua junto. Dessa forma, a força de trabalho dessas mulheres é exercida de acordo com a necessidade do dia a dia. Por exemplo, uma das entrevistadas aponta que: "[...] há dias que fico responsável apenas por molhar e cuidar das plantinhas, mas há dias que preciso ir às feiras para vender também [...]".
Portanto, apesar de existirem desigualdades entre os gêneros que compõem a força de trabalho, a pesquisa aponta que o turismo rural configura-se como um ramo de atividade que possibilita uma atuação de forma mais igualitária entre os gêneros, no qual mulheres mesmo com baixa escolaridade conseguem se inserir.

Quando questionadas sobre suas perspectivas futuras, uma das entrevistadas aponta que "o turismo rural me trouxe meIhoria na sua qualidade de vida, pretendo me manter no mercado de trabalho, acredito que o turismo rural tem futuro e pretendo continuar nesse segmento/mercado de trabalho".

Conforme visto por Lunardi, Souza e Perurena (2015), o turismo rural estabeleceu um processo de mudança da identidade social e profissional do ser humano, pois a muIher passa a compor o mercado de trabalho sendo reconhecida como "empresária do turismo", reforçando sua identidade de agricultora, uma vez que o turismo rural tem como principal característica a relação direta com alguma atividade tradicionalmente exercida no campo. Dessa forma, o turismo rural implementado nas propriedades do Circuito Rajadinha é visto pelas mulheres que ali atuam como um impulsionador da inserção da mão de obra feminina no mercado de trabalho e exige dedicação e empenho.

Verificou-se que o turismo rural mostra-se eficiente economicamente e socialmente, pois a pesquisa apontou que as muIheres entrevistadas mostram-se realizadas. São mulheres que buscaram a inserção no mercado de trabalho em busca de recursos para complementar a renda família. Porém, o 
turismo rural possibilitou a elas ganhos mais significativos, apontado por elas mesmas, como o conhecimento e experiência adquiridos, bem como o reconhecimento de sua força de trabalho que as fazem ter uma perspectiva futura positiva em relação ao ramo do turismo rural em que atuam. Todas as entrevistadas apontam que querem permanecer no segmento e buscam incessantemente conhecer cada vez mais sobre o setor, rumo a patamares mais altos no mercado de trabaIho.

Visando um comparativo entre o levantamento teórico realizado e os dados obtidos com a pesquisa de campo realizada no Circuito Rajadinha, o Quadro 1 apresenta de forma compacta os resultados do estudo sobre gênero e turismo rural.

Quadro 1 - Comparativo entre a teoria e os resultados da pesquisa

\begin{tabular}{|c|c|}
\hline Teoria & Resultados encontrados no Circuito Rajadinha \\
\hline $\begin{array}{l}\text { Mudanças no perfil do mercado de traba- } \\
\text { lho e das relações sociais (Alves, Lima \& } \\
\text { Nagabe, 2016; Freitas \& Reis, 2015). }\end{array}$ & $\begin{array}{l}\text { Confirmação no Circuito Rajadinha, pois constatou-se a pre- } \\
\text { sença da força de trabalho feminina em todas as propriedades } \\
\text { investigadas. }\end{array}$ \\
\hline $\begin{array}{l}\text { Crescimento da participação da mulher no } \\
\text { mercado de trabalho explicado pelo au- } \\
\text { mento do custo de vida e quebra da econo- } \\
\text { mia (Kloster et al, 2015; Priore } 1997 \text { apud } \\
\text { Ramos, Ulbanere \& Jesus, 2014). }\end{array}$ & $\begin{array}{l}\text { Confirmação no levantamento realizado, destaca-se o relato } \\
\text { de que "entrei no mercado de trabalho porque precisava fazer } \\
\text { algo remunerado, antes não tive oportunidade devido a falta } \\
\text { de estudo [...]" }\end{array}$ \\
\hline $\begin{array}{l}\text { O turismo traz implícitos valores sociais } \\
\text { (Lunardi, Souza \& Perurena, 2015). }\end{array}$ & $\begin{array}{l}\text { Confirmação na pesquisa realizada, pois conforme uma entre- } \\
\text { vistada: "[...] dificuldades a gente encontra diariamente, e no } \\
\text { nosso trabalho a gente encontra também, mas não desanimo } \\
\text { porque já ganhei muito até chegar aqui e posso ganhar mais } \\
{[\ldots . .] " .} \\
\text { Os resultados da inserção tomaram rumos diferentes: melhoria } \\
\text { na qualidade de vida por meio da experiência e do conheci- } \\
\text { mento adquirido. }\end{array}$ \\
\hline $\begin{array}{l}\text { Mão de obra feminina é uma ajuda, um } \\
\text { complemento (Herrera, 2013; Schmitz \& } \\
\text { Santos, 2013). }\end{array}$ & $\begin{array}{l}\text { Quebra desse paradigma, pois são as mulheres que estão à } \\
\text { frente das atividades relacionadas ao turismo rural e até } \\
\text { mesmo em todas as atividades inerentes ao campo. } \\
\text { Ressalta-se que em duas chácaras as proprietárias são mulhe- } \\
\text { res. }\end{array}$ \\
\hline $\begin{array}{l}\text { Divisão sexual do trabalho - Homem = es- } \\
\text { fera produtiva e mulher = esfera reprodu- } \\
\text { tiva (Faria } 2009 \text { apud Nascimento, 2013). }\end{array}$ & $\begin{array}{l}\text { Todas as entrevistadas atuam em diferentes partes da cadeia } \\
\text { produtiva dos seus respectivos negócios: "[...] há dias que fico } \\
\text { responsável apenas, por molhar e cuidar das plantinhas, mas } \\
\text { há dias que preciso ir às feiras para vender também [...]". }\end{array}$ \\
\hline $\begin{array}{l}\text { A mulher reconhecida como empresária do } \\
\text { turismo rural (Lunardi, Souza \& Perurena, } \\
\text { 2015). }\end{array}$ & $\begin{array}{l}\text { A inserção da mulher enquanto elemento considerado essen- } \\
\text { cial pelos proprietários entrevistados remete ao reconheci- } \\
\text { mento da força de trabalho feminina. } \\
\text { Segundo relato de um proprietário, "muita coisa melhorou aqui } \\
\text { na propriedade com a participação da mulher nas atividades } \\
\text { que fazemos". }\end{array}$ \\
\hline
\end{tabular}

Fonte: Dados primários 
Dessa forma, compreende-se que o meio rural promove a multifuncionalidade através do turismo e outras atividades não agrícolas. Além de promover benefícios econômicos como emprego e renda, o turismo rural promove para as mulheres investigadas benefícios sociais, que vão desde a manutenção no campo e melhoria na qualidade de vida, até benefícios intangíveis como o aumento da autoestima devido o reconhecimento de seu trabalho, conquista de conhecimento e perspectiva de novos horizontes.

\section{CONSIDERAÇÕES FINAIS}

Dentre a gama de mudanças advindas no contexto da modernização e da globalização, o campo torna-se multifuncional onde diversas atividades não agrícolas passam a ser desenvolvidas nesse meio. Uma dessas atividades refere-se ao turismo. Observa-se que no turismo no espaço rural os moradores locais buscam novas estratégias para sua manutenção do campo. Dessa forma, o turismo no espaço rural refere-se a toda e qualquer forma de atividade turística desenvolvida no espaço rural. Consiste em uma modalidade turística do espaço rural, diferenciando-se das demais modalidades já que se refere ao conjunto de atividades no qual a agricultura e a pecuária - atividades tradicionais ao campo - devem estar relacionadas à oferta do produto turístico.

Sob este aspecto, o presente estudo analisou a inserção da mulher no cenário do turismo rural na região de Planaltina-DF. Para tanto teve como objeto o levantamento rea- lizado no Circuito Rajadinha, Projeto criado em 2014 com o propósito de integrar atividades turísticas aos arranjos produtivos locais da agricultura familiar. Assim, das dez propriedades que integram o Circuito, foi possível investigar oito e nelas pesquisou-se dez muIheres que trabalham no contexto do turismo rural.

Constatou-se no Circuito Rajadinha que o turismo rural estabelecido nas oito propriedades investigadas possui um viés social, pois foi através dele que as dez mulheres pesquisadas ingressaram no mercado de trabalho. Verificou-se que essas mulheres conquistaram um espaço ao qual o homem sempre deteve toda a força de trabalho.

Entende-se que o espaço rural era considerado o "espaço do homem", no qual este se responsabilizava pela produção, sendo o detentor da força de trabalho. Contudo, observou-se no Circuito Rajadinha uma mudança no perfil das relações de trabalho, pois notou-se a presença da mulher em todas as atividades desenvolvidas pelas propriedades investigadas.

Destaca-se que duas propriedades investigadas são conduzidas integralmente por mulheres, onde estas são responsáveis por todas as atividades inerentes ao espaço que vivem. Dessa forma, confirma-se uma quebra do paradigma de que as atividades desenvolvidas no campo seriam "atividades masculinas", pois essas mulheres que atuam no Circuito são protagonistas para o desencadeamento das atividades turísticas desenvolvidas nas propriedades que compõem o Projeto.

O estudo remete a conclusão de que 
a mulher é capaz de assumir qualquer ramo de atividade no mercado de trabalho, desde que Ihes sejam dadas oportunidades. Na região de Planaltina-DF, o Circuito Rajadinha é apontado pelas dez mulheres investigadas como a oportunidade dada para atuarem num cenário marcado por diversas peculiar dades. Elas são vistas pelos proprietários das chácaras que compõem o Circuito como elementos importantes e até mesmo cruciais no desenvolvimento do turismo rural da região.

Assim, constata-se que a mulher vem ganhando cada vez mais espaço e sua mão de obra começa a ser valorizada, deixando de ser vista apenas com um complemento e sim como elemento essencial nas atividades desempenhadas no Circuito. Mulher esta que se faz multifuncional, pois é capaz de ser mãe, esposa e profissional.

A pesquisa aponta que foi em busca de melhoria na qualidade de vida e de renda que essas mulheres atuantes no Circuito buscaram se inserir no segmento, porém foi visto que esta inserção trouxe outros benefícios como o reconhecimento, a autoestima e a aprendizagem. Assim, essas mulheres merecem o mérito de serem reconhecidas como peças chaves para o desencadeamento deste ramo que cresce na região.

Por fim, é necessário mencionar que o estudo apresentou algumas limitações, pois o Circuito Rajadinha, por ser um projeto relativamente novo, possui poucas propriedades atuantes. Além disso, não foi possível entrevistar dois estabelecimentos do Circuito. No entanto, o trabalho foi gratificante por ser possível constatar a realidade de muIheres do campo, que embora retraídas pelo medo de não atender as perspectivas do estudo, se mostraram abertas a ajudar e, na simplicidade, proporcionaram uma experiência única e de suma importância para a concretização deste artigo.

\section{AGRADECIMENTOS}

Agradecimentos a Empresa de Assistência Técnica e Extensão Rural do Distrito Federal (Emater-DF) que, por meio da Turismóloga Zaida Regina da Silva, nos forneceu todas as informações necessárias para o êxito na execução deste trabalho.

\section{REFERÊNCIAS}

Alves, H. H., Lima, L. C. B. \& Nagabe, F. (2016). Turismo e cooperação feminina: o caso da Cooperativa Flores do Brejo de Pilões, Paraíba. Caderno de Estudos e Pesquisas do Turismo, 5 (6), p. 4-21, jan/jun.

Amaral, M. I. C. (2016). Cooperação entre os Stakeholders e o Desenvolvimento Turístico dos Territórios Rurais - O Caso da Sub-Região do Baixo Alentejo (Alentejo - Portugal). Revista Turismo - Visão e Ação, 18(1), p. 29-59. DOI: https://doi.org/10.14210/rtva.v18n1.p29-59

Chácara Isabelas. Circuito Tur. Santana Barreiros e Brasileiro. Disponível em: <http://www.chacaraisasbelas.com.br/circuito_tur_37.html >. Acesso em: 23 nov.2017.

Cezário, J. H. A., Mestre, E. F. G. \& Baptista, L. (2015). Adaptação de Propriedade para o Turismo no Meio Rural: Estudo de Caso Sobre o Recanto Daneliv no Município de Irati - PR. Caderno de Estudos e Pesquisas do Turismo, 4(4), p. 39-55, jan./jun.

Freitas, P. \& Reis, S. S. (2015). Mercado de Trabalho e Questões de Gênero: Avanços e 
Perspectivas. XII Seminário Internacional de Demandas Sociais e Políticas Públicas na Sociedade Contemporânea, Universidade de Santa Cruz do Sul.

Guerra, E. L. A. (2014). Manual pesquisa qualitativa. Belo Horizonte: Grupo Ănima Educação.

Gerhardt, T. E. \& Silveira, D. T. (2009). Métodos de Pesquisa. Rio Grande Sul: UFRGS.

Herrera, K. M. (2013). Uma Análise do Trabalho da Mulher Rural Através da Perspectiva da Multifuncionalidade Agrícola. Seminário Internacional Fazendo Gênero 10, Florianópolis.

Kloster, S. et al. (2015). O Papel Feminino e Campo: Olhares por meio do Turismo Rural. Anais Semana de Geografia, 1(1), p. 102-106, Ponta Grossa: UEPG.

Lunardi, R., Souza, M. \& Perurena, F. (2015). O Trabalho de Homens e Mulheres no Turismo Rural em São José dos Ausentes: o "leve" e o "pesado". Revista Turismo - Visão e Ação, 17(1), p. 179-209. DOI:

https://doi.org/10.14210/rtva.v17n1.p179-209

Maia, E. M. M. (2015). Turismo rural na agricultura familiar: um estudo de caso no Assentamento Tijuca Boa Vista em Quixadá (CE). Caderno Virtual de Turismo, 15(1), p. 1-19.

Martimon, A. (2016). Agência Brasília. Conheça o Circuito Rajadinha. Disponível em:

$<$ https://www.agenciabrasilia.df.gov.br/2016/07/24/conheca-o-circuito-rajadinha-em-planaltina/>. Acesso em: 27 nov. 2017.

Martins, R. X. (2013). Metodologia de Pesquisa: Guia de Estudos. Lavras: UFLA. DOI: https://doi.org/10.1123/pes.25.1.3

Ministério do Desenvolvimento Agrário (MDA). (2017). Secretaria Especial de Agricultura Familiar e do Desenvolvimento Agrário.
Coordenação de Flávia Dias. Disponível em: <http://www.mda.gov.br/portalmda/noticias/agricultores-familiares-recebem-turistasno-distrito-federal>. Acesso em: 15 mai. 2017.

Nascimento, P. F. (2013). Turismo Rural nas Montanhas Capixabas: como vivem e trabalham mulheres e homens em um campo em transformação. Dissertação (Magister Scientiae)- Universidade Federal de Viçosa, Viçosa - MG.

Oliveira, M. F. (2011). Metodologia científica: um manual para a realização de pesquisas em Administração. Catalão: UFG.

Pato, L. (2015). A Construção e Desenvolvimento do Turismo no Espaço Rural em Portugal: o papel da administração central nos seus conteúdos. Revista Turismo em Análise, 26 (4), p. 919-932. DOI: https://doi.org/10.11606/issn.19844867.v26i4p919-932

Prodanov, C. C. \& FREITAS, E. C. (2013). Metodologia do trabalho científico: Métodos e Técnicas da Pesquisa e do Trabalho Acadêmico. 2. ed. Novo Hamburgo: Feevale.

Ramalho, M. M. C. (2016). Estudos sobre o Turismo no Espaço Rural em Barra do Pirai e sua Relação com o Desenvolvimento. Revista Turismo-Visão e Ação, 18(2), p. 223-250. DOI: https://doi.org/10.14210/rtva.v18n2.p223-250

Ramos, M. O., Ulbanere, R. C. \& Jesus, B. S. (2014). Mulheres no Mercado de Trabalho. Revista Cientifica integrada, ed. 4, p. 1498-1506.

Santos, E. O. et al. (2014). Campos de Cima da Serra e o turismo no espaço rural. Revista Turismo-Visão e Ação, 16(2), p. 248-272. DOI: https://doi.org/10.14210/rtva.v16n2.p248

Scótolo, D.\& Netto, A. P. (2015). Contribuições do Turismo para o Desenvolvimento Local. Revista de Cultura e Turismo, 9(1), p. 36-59. 
Schmitz, A. M \& Santos, R. S. (2013). A Divisão Sexual do Trabalho na Agricultura Familiar. Seminário Internacional Fazendo Gênero 10, UFSC, Florianópolis.

Informações dos autores:

\section{Donária Coelho Duarte}

Mestre e Doutora em Engenharia de Produção pela Universidade Federal de Santa Catarina. Graduada em Ciências da Administração pela Universidade Federal de Santa Catarina. Professora Adjunta da Universidade de Brasília - Campus Planaltina. Membro efetivo do Laboratório de Estudos em Turismo e Sustentabilidade (LETS/UnB)

Email: donaria@hotmail.com

ORCID: 0000-0001-7673-0227

\section{Ana Darc Jesus Pereira}

Graduada em Gestão do Agronegócios pela Universidade de Brasília - Campus Planaltina. Estagiária da Agência Eletrobras Eletronorte. Email: anadarcjpereira@gmail.com ORCID: 0000-0002-3140-4839 